\title{
Associations between pre-pregnancy body mass index and gestational weight gain with pregnancy outcomes in women with polycystic ovary syndrome
}

\author{
Lirui Zhang, Wei Zheng, Cheng Liu, Xin Liang, Li Zhang, Zhihong Tian and Guanghui Li* ${ }^{*}$
}

\begin{abstract}
Background: The influence of pre-pregnancy body mass index (BMI) and gestational weight gain (GWG) on perinatal outcomes of women with polycystic ovary syndrome (PCOS) remains unclear. Therefore, we explored how the above indicators influence pregnancy outcomes in women with PCOS.

Methods: A retrospective study was conducted involving the baseline characteristics, laboratory data, and pregnancy outcomes of 722 pregnant women with PCOS. Subjects were grouped in a way to find out risks in their pregnancy outcomes. Multivariable logistic regression analysis was performed to investigate how BMI and GWG were associated with perinatal outcomes.

Results: Among women with PCOS, underweight increased the risk of small for gestational age (SGA) (OR 12.35, 95\% $\mathrm{Cl}$ 3.56-42.82), but reduced the risk of large for gestational age (LGA). Overweight but not obese women were more susceptible to developing preeclampsia (PE) than women with normal weight. In PCOS women with $\mathrm{BMl}<25 \mathrm{~kg} /$ $\mathrm{m}^{2}$ before pregnancy, inadequate GWG was a protective factor for gestational hypertension (GH) and postpartum hemorrhage (PPH), excessive GWG exhibited a positive correlation with LGA. But in PCOS women with BMI $\geq 25 \mathrm{~kg}$ / $\mathrm{m}^{2}$, excessive GWG increased the probability of undergoing a cesarean section. Inadequate GWG did not reduce the likelihood of LGA in women with $\mathrm{BMI} \geq 25 \mathrm{~kg} / \mathrm{m}^{2}$, and excessive GWG did not reduce the probability of SGA in women with $\mathrm{BMl}<25 \mathrm{~kg} / \mathrm{m}^{2}$.

Conclusion: The impacts of pre-pregnancy BMI, GWG on maternal and infant outcomes among PCOS women are similar to reported results in general pregnant women. However, some unique trends were also observed in PCOS women. While the underweight factor significantly increased the risk of SGA birth, overweight but not obesity was correlated with the risk of PE. Inadequate GWG was a protective factor for GH and PPH only in women with pregestational $\mathrm{BMI}<25 \mathrm{~kg} / \mathrm{m}^{2}$. Inadequate GWG did not reduce the probability of $\mathrm{LGA}$ in women with $\mathrm{BMI} \geq 25 \mathrm{~kg} / \mathrm{m}^{2}$, and similarly, excessive GWG did not reduce the probability of SGA in women with $B M l<25 \mathrm{~kg} / \mathrm{m}^{2}$. Overall, these findings indicate that women with PCOS should begin weight management before pregnancy.
\end{abstract}

Keywords: Pregnancy, Polycystic ovary syndrome, Body mass index, Gestational weight gain, Pregnancy outcome

*Correspondence: liguanghui2007@163.com

Division of Endocrinology and Metabolism, Department of Obstetrics, Beijing Obstetrics and Gynecology Hospital, Capital Medical University, No 251, Yaojiayuan Road, Chaoyang District, Beijing 100026, China

\section{Background}

Polycystic ovary syndrome (PCOS), a common heterogeneous female endocrinopathy affecting approximately 5 to $20 \%$ of women of childbearing age worldwide [1],

c) The Author(s) 2020. This article is licensed under a Creative Commons Attribution 4.0 International License, which permits use, sharing, adaptation, distribution and reproduction in any medium or format, as long as you give appropriate credit to the original author(s) and the source, provide a link to the Creative Commons licence, and indicate if changes were made. The images or other third party material in this article are included in the article's Creative Commons licence, unless indicated otherwise in a credit line to the material. If material is not included in the article's Creative Commons licence and your intended use is not permitted by statutory regulation or exceeds the permitted use, you will need to obtain permission directly from the copyright holder. To view a copy of this licence, visit http://creativeco mmons.org/licenses/by/4.0/. The Creative Commons Public Domain Dedication waiver (http://creativecommons.org/publicdomain/ zero/1.0/) applies to the data made available in this article, unless otherwise stated in a credit line to the data. 
is characterized by hyperandrogenemia, hyperinsulinemia, and insulin resistance [2]. In recent years, the advancement in assisted reproductive technology has significantly increased the chances of pregnancy in PCOS women. However, this condition has increased the risk of complications during pregnancy or delivery, such as the prevalence of gestational diabetes mellitus (GDM), preeclampsia (PE), and premature delivery [3]. For instance, women with PCOS are more susceptible to overweight/obesity and experience higher GWG, than their normal counterparts $[4,5]$. This may be, in part, due to neurohormonal gut-brain interactions in women with PCOS [6]. GWG in women is crucial to optimize maternal, fetal, and neonatal health, with previous studies associating inappropriate pre-pregnancy BMI and GWG with higher risks of adverse neonatal and maternal outcomes in general pregnant women [7-10]. However, few studies have described the impact of both pre-pregnancy BMI and GWG on maternal and infant outcomes of these special individuals. In light of this, our study investigated the effect of pre-pregnancy BMI and GWG on pregnancy outcomes of PCOS women, with the view of generating vital information to guide proper weight management before or during pregnancy and reduce related adverse maternal and infant outcomes.

\section{Materials and methods Study subjects}

The present study was a retrospective cohort study comprising 722 PCOS women who established a medical record for receiving healthcare in the first trimester of pregnancy and delivered live-born singletons at the Beijing Obstetrics and Gynecology Hospital, Capital Medical University between July, 2017 and July, 2019. Participants were included in the study if they; (i) were women diagnosed with PCOS; (ii) were pregnant; (iii) were aged between 18 and 45 years; and (iv) had a singleton pregnancy. On the other hand, subjects were excluded if they; (i) were females with multiple pregnancies; (ii) had preexisting hypertension, diabetes, acute and chronic heart, liver, kidney disease, or other serious diseases; (iii) exhibited fetal chromosomal abnormalities or major birth defects and; (iv) did not have complete clinical data. The study received ethical approval from the ethics committee of the Beijing Obstetrics and Gynecology Hospital affiliated with Capital Medical University, with all the participants signing informed consent documents prior to inclusion.

\section{Study design}

PCOS diagnosis was based on the revised 2003 Rotterdam Criteria, which requires the presence of 2 of the following 3 criteria: (i) oligo- or anovulation, (ii) clinical and, or biochemical signs of hyperandrogenism, and (iii) polycystic ovaries and exclusion of other etiologies (congenital adrenal hyperplasia, androgensecreting tumors, Cushing's syndrome) [11]. We used the electronic medical record system of the hospital to collect the patient-level variables, such as standard demographic information (age, pre-pregnancy height and weight, GWG, number of prior pregnancies, parity, and family history) and relevant maternal and infant outcomes, as well as laboratory data. Pre-pregnancy BMI, calculated as weight divided by height squared $\left(\mathrm{kg} / \mathrm{m}^{2}\right)$ using self-reported pre-pregnancy weight, was used to categorize the subjects into 4 groups, according to World Health Organization (WHO)'s guidelines. Based on these criteria, individuals with a BMI of $<18.5$, $18.5-24.9,25.0-29.9$, and $\geq 30 \mathrm{~kg} / \mathrm{m}^{2}$, were classified as underweight, normal weight, overweight, and obese, respectively. Maternal GWG, calculated as weight before delivery minus the pre-pregnancy weight, was used to group the subjects into within or above the target as recommended by the Institute of Medicine (IOM). Based on these guidelines, different weight gain intervals exist based on pregestational BMI (Table 1). Weight gains of $12.5-18,11.5-16,7-11.5$, and 5-9 kg are recommended for underweight, normal weight, overweight, and obese women, respectively. Gestational weight gains below or above the recommended threshold were defined as inadequate or excessive weight gains, respectively. Then, the association between maternal pre-pregnancy BMI, GWG clinical categories, and the risk of some perinatal outcomes among PCOS women, which have been rarely investigated, were explored in our study.

\section{Pregnancy outcome}

Gestational hypertension (GH) was defined as de novo hypertension, if an individual exhibited a systolic blood pressure $\geq 140 \mathrm{mmHg}$ and, or diastolic blood pressure $\geq 90 \mathrm{mmHg}$, after 20 weeks of pregnancy [12], whereas preeclampsia (PE) was defined by the onset of

\begin{tabular}{|c|c|c|}
\hline $\begin{array}{l}\text { Pre-pregnancy weight } \\
\text { category }\end{array}$ & $\begin{array}{l}\text { Body mass index } \\
\left(\mathrm{kg} / \mathrm{m}^{2}\right)\end{array}$ & $\begin{array}{l}\text { Recommended } \\
\text { range of total } \\
\text { weight }(\mathrm{kg})\end{array}$ \\
\hline Underweight & $<18.5$ & $12.5-18.0$ \\
\hline Normal weight & $18.5-24.9$ & $11.5-16.0$ \\
\hline Overweight & $25.0-29.9$ & $7.0-11.5$ \\
\hline Obese & $\geq 30$ & $5.0-9.0$ \\
\hline
\end{tabular}


hypertension and proteinuria, after 20 weeks of gestation [13]. Gestational diabetes mellitus (GDM) diagnosis was based on the result of a standard $75 \mathrm{~g}$ oral glucose tolerance test between 24 and 28 weeks of gestation, if any one of the following criteria was met: plasma glucose $\geq 5.1 \mathrm{mmo} / \mathrm{L}, \geq 10.0 \mathrm{mmol} / \mathrm{L}$, and $\geq 8.5 \mathrm{mmol} / \mathrm{L}$ for fasting, 1 and $2 \mathrm{~h}$ respectively. Postpartum hemorrhage $(\mathrm{PPH})$ was defined as blood loss $\geq 500 \mathrm{~mL}$ within $24 \mathrm{~h}$ of delivery. Small for gestational age (SGA) was defined as a birth weight below the 10th percentile for gestational age and gender, whereas large for gestational age (LGA) was defined as a birth weight above the 90th percentile for gestational age and gender [14]. Lastly, macrosomia was defined as a birth weight $\geq 4000 \mathrm{~g}$, whereas assisted vaginal delivery was defined as forceps or vacuum and assisted breech delivery.

\section{Statistical analyses}

All data were evaluated using the SPSS 23.0 software, and the results were presented as means \pm standard deviations (SD) of the means. Enumeration data were analyzed using the Chi-square test, multivariable logistic regression analysis was applied to assess the correlation between BMI, and GWG with pregnancy outcomes, after controlling for relevant confounding factors, such as maternal age, height, pre-pregnancy BMI, gravidity, parity, gestational age at delivery, weight gain during pregnancy, cigarette smoke and alcohol consumption pre-pregnancy. A value of $\mathrm{P}<0.05$ was regarded as statistically significant.

\section{Results}

Of the 722 women with PCOS included in the study, $83.5 \%$ were primiparas, and $16.5 \%$ were multiparas. The average maternal age $( \pm \mathrm{SD})$ was $31.7 \pm 6.1$ years, gestational age was $38.7 \pm 1.7$ weeks, and the average prepregnancy BMI was $23.6 \pm 1.7 \mathrm{~kg} / \mathrm{m}^{2}$. Among the 722 subjects, 47 (6.5\%), 460 (63.7\%), 152 (21.1\%), and 63 (8.7\%) were underweight, normal weight, overweight, and obese, respectively, prior to pregnancy. Approximately 169 (23\%), 323 (45\%), and 230 (32\%) women experienced inadequate, adequate, and excessive weight gain during pregnancy, respectively, according to the 2009 IOM guidelines. Analysis of the pregnancy outcomes revealed that $22.6 \%, 12.3 \%, 5.4 \%$, and $10.9 \%$ of the study subjects developed GDM, GH, PE, and $\mathrm{PPH}$, respectively. Regarding the mode of delivery, $56.8 \%, 8.3 \%$, and $34.9 \%$ of the women required vaginal, assisted vaginal, and cesarean section delivery, respectively. Furthermore, $8.7 \%, 1.8 \%$, and $18.8 \%$ of the newborns were macrosomia, SGA, and LGA, respectively.

Table 2 shows the relationship between pre-pregnancy BMI and the pregnancy outcomes. Compared with the women with normal weight before pregnancy, underweight women were positively correlated with the risk of SGA birth (OR 12.35, 95\% CI 3.56-42.82) and vaginal delivery (OR 2.21, 95\% CI 1.09-4.50), but were negatively correlated with the risk of LGA (OR 0.21, 95\% CI 0.050.88 ). Overweight and obese women had increased risk of developing gestational hypertension (OR 4.86, 95\% CI 2.82-8.39; and OR 6.05, 95\% CI 2.97-12.33, respectively), undergoing cesarean section delivery (OR 1.71, 95\% CI

Table 2 The relationship between BMI categories and maternal/fetal outcomes

\begin{tabular}{lccc}
\hline Outcome & $\begin{array}{l}\text { Underweight } \\
\text { Adjusted OR 95\% Cl }\end{array}$ & $\begin{array}{l}\text { Overweight } \\
\text { Adjusted OR 95\% Cl }\end{array}$ & $\begin{array}{l}\text { Obesity } \\
\text { Adjusted OR 95\% Cl }\end{array}$ \\
\hline GH & $0.24[0.03-1.80]$ & $4.86[2.82-8.39]^{* *}$ & $6.05[2.97-12.33]^{* *}$ \\
PE & $0.55[0.07-4.29]$ & $4.08[1.95-8.51]^{* *}$ & $1.46[0.40-5.37]$ \\
GDM & $0.56[0.21-1.51]$ & $1.33[0.85-2.09]$ & $1.23[0.65-2.32]$ \\
PPH & $0.18[0.02-1.35]$ & $1.60[0.91-2.81]$ & $1.88[0.83-4.24]$ \\
Cesarean section & $0.55[0.25-1.20]$ & $1.71[1.15-2.55]^{*}$ & $2.10[1.18-3.74]^{*}$ \\
Assisted vaginal delivery & $0.36[0.08-1.56]$ & $0.50[0.23-1.12]$ & $0.41[0.12-1.42]$ \\
Vaginal delivery & $2.21[1.09-4.50]^{*}$ & $0.75[0.51-1.09]$ & $0.65[0.37-1.14]$ \\
Macrosomia & $0.46[0.10-2.07]$ & $2.15[1.14-4.05]^{*}$ & $1.54[0.52-4.55]$ \\
SGA & $12.35[3.56-42.82]^{* *}$ & $0.41[0.05-3.62]$ & $\mathrm{NS}$
\end{tabular}

Data was analyzed using multivariable logistic regression analysis. Models were adjusted for maternal age, height, gravidity, parity, gestational age at delivery, weight gain during pregnancy, cigarette smoke pre-pregnancy, and alcohol consumption pre-pregnancy

Reference group: normal weight for pre-pregnancy

$O R$ odds ratio, $C l$ confidence interval, $G H$ gestational hypertension, $P E$ preeclampsia, GDM gestational diabetes mellitus, $P P H$ postpartum hemorrhage, SGA small for gestational age, LGA large for gestational age, NS the number in this category was too small to analyze

${ }^{*} \mathrm{P}<0.05$

**P $<0.001$ 
1.15-2.55; and OR 2.10, 95\% CI 1.18-3.74, respectively), and having an infant with LGA (OR 2.57, 95\% CI 1.644.04; and OR 2.22, 95\% CI 1.12-4.39, respectively). Overweight women were more likely to develop PE (OR 4.08, 95\% CI 1.95-8.51) and result in macrosomia at birth (OR 2.15, 95\% CI 1.14-4.05) when compared with normal weight PCOS women.

As Table 3 shows, significantly lower $(\mathrm{P}<0.05)$ incidences of GH and PPH were observed in the inadequate GWG groups, whereas significantly higher $(P<0.001)$ LGA and macrosomia incidences were reported in the excessive GWG group relative to the other 2 groups. The results from multivariate logistic regression demonstrated that compared with the women in the adequate GWG group, individuals in the inadequate GWG group had a lower risk of developing GH (OR 0.28, 95\% CI 0.12-0.66) and PPH (OR 0.38, 95\% CI 0.17-0.84), while those in the excessive GWG group were more likely to deliver macrosomia (OR 1.93, 95\% CI 1.05-3.54) and give birth to LGA infants (OR 1.94, 95\% CI 1.27-2.96). Further subgroup analyses based on stratification of body mass indices revealed that when compared with the adequate GWG group women with the same BMI, inadequate GWG decreased the risks of GH (OR 0.24, 95\% CI $0.08-0.71$ ) and PPH (OR 0.38, 95\% CI 0.16-0.95) in women with $\mathrm{BMI}<25 \mathrm{~kg} / \mathrm{m}^{2}$ before pregnancy (Table 4 ). Moreover, excessive GWG was related to the higher possibility of LGA birth (OR 2.41, 95\% CI 1.40-4.18) in women with $\mathrm{BMI}<25 \mathrm{~kg} / \mathrm{m}^{2}$, as well as the likelihood of undergoing a cesarean section (OR 2.06, 95\% CI 1.014.20 ) in women with $\mathrm{BMI} \geq 25 \mathrm{~kg} / \mathrm{m}^{2}$ (Table 5).

\section{Discussion}

Our results showed a positive association between women who were underweight, prior to pregnancy, with the incidence of SGA infants, and a negative relationship between this group of women with the incidence of LGA infants. We also found that pre-pregnancy overweight but not obesity was more susceptible to developing PE. Furthermore, GWG below the recommended level significantly reduced the risk for $\mathrm{GH}$, and $\mathrm{PPH}$ in women with pre-pregnancy $\mathrm{BMI}<25 \mathrm{~kg} / \mathrm{m}^{2}$, whereas that above the recommended threshold increased the chances of cesarean section in those with a pre-pregnancy BMI $\geq 25 \mathrm{~kg} /$ $\mathrm{m}^{2}$. For women with $\mathrm{BMI} \geq 25 \mathrm{~kg} / \mathrm{m}^{2}$, GWG below the recommendation did not reduce the likelihood of LGA, and GWG above the recommendation did not reduce the probability of SGA in women with $\mathrm{BMI}<25 \mathrm{~kg} / \mathrm{m}^{2}$.

Our findings further indicated that pre-pregnant underweight PCOS women were at a significantly higher risk of SGA but at a lower risk for LGA, relative to normal weight PCOS counterparts. Particularly, underweight PCOS women had a 12-fold risk of having SGA compared with normal weight counterparts, which was much higher than general underweight women in China and Lebanon (OR 1.67, 95\% CI 1.49-1.87 and OR 1.50, $95 \%$ CI $1.37-1.63$, respectively) $[15,16]$. PCOS in pregnancy can involve elevated androgen concentration level, which might affect fetal outcomes [17]. Therefore, the superposition effect of PCOS and underweight state may contribute to this result. Furthermore, GWG above the recommendation exhibited a significantly positive correlation with LGA birth in women with $\mathrm{BMI}<25 \mathrm{~kg} / \mathrm{m}^{2}$,

Table3 The relationship between GWG categories and maternal/fetal outcomes

\begin{tabular}{|c|c|c|c|c|c|c|}
\hline \multirow[t]{2}{*}{ Outcome } & \multicolumn{4}{|c|}{ Pregnancy outcomes by gestational weight gain category } & \multicolumn{2}{|c|}{ Multivariable logistic regression analyses } \\
\hline & $\begin{array}{l}\text { Inadequate } \\
(\mathrm{N}=169)\end{array}$ & Adequate $(\mathrm{N}=323)$ & Excessive $(\mathrm{N}=230)$ & P-value & $\begin{array}{l}\text { Inadequate weight } \\
\text { gain }\end{array}$ & Excessive weight gain \\
\hline $\mathrm{GH}(\mathrm{N})$ & $7(4.1 \%)$ & $42(13 \%)$ & $40(17.4 \%)$ & $<0.001$ & $0.28[0.12-0.66]$ & $1.15[0.69-1.91]$ \\
\hline $\mathrm{PE}(\mathrm{N})$ & $5(3 \%)$ & $17(5.3 \%)$ & $17(7.4 \%)$ & 0.15 & $0.56[0.20-1.56]$ & $1.36[0.66-2.78]$ \\
\hline $\mathrm{GDM}(\mathrm{N})$ & $64(37.9 \%)$ & $69(21.4 \%)$ & $30(13 \%)$ & $<0.001$ & $2.30[1.49-3.54]$ & $0.49[0.30-0.80]$ \\
\hline $\mathrm{PPH}(\mathrm{N})$ & $8(4.7 \%)$ & $38(11.8 \%)$ & $33(14.3 \%)$ & 0.008 & $0.38[0.17-0.84]$ & $1.21[0.73-2.04]$ \\
\hline Cesarean section $(\mathrm{N})$ & $56(33.1 \%)$ & $108(33.4 \%)$ & $88(38.3 \%)$ & 0.43 & 0.88 [0.58-1.34] & 1.28 [0.88-1.87] \\
\hline $\begin{array}{l}\text { Assisted vaginal } \\
\text { delivery }(\mathrm{N})\end{array}$ & $14(8.3 \%)$ & $30(9.3 \%)$ & $16(7.0 \%)$ & 0.62 & 0.97 [0.49-1.92] & $0.64[0.34-1.24]$ \\
\hline Vaginal delivery (N) & 99 (58.6\%) & $185(57.3 \%)$ & $126(54.8 \%)$ & 0.73 & $1.13[0.76-1.67]$ & $0.91[0.64-1.29]$ \\
\hline Macrosomia (N) & $7(4.1 \%)$ & $22(6.8 \%)$ & $34(14.8 \%)$ & $<0.001$ & $0.67[0.27-1.66]$ & $1.93[1.05-3.54]$ \\
\hline SGA (N) & $4(2.4 \%)$ & $5(1.5 \%)$ & $4(1.7 \%)$ & 0.72 & $1.23[0.31-4.87]$ & $1.25[0.32-4.95]$ \\
\hline LGA (N) & $18(10.7 \%)$ & $53(16.4 \%)$ & $72(31.3 \%)$ & $<0.001$ & $0.65[0.36-1.17]$ & $1.94[1.27-2.96]$ \\
\hline
\end{tabular}

Multivariable logistic regression analysis was adjusted for maternal age, height, gravidity, parity, gestational age at delivery, pre-pregnancy BMI, cigarette smoke prepregnancy, and alcohol consumption pre-pregnancy

Reference group: adequate GWG group

$N$ number of cases, GH gestational hypertension, $P E$ preeclampsia, GDM gestational diabetes mellitus, $P P H$ postpartum hemorrhage, SGA small for gestational age, LGA large for gestational age 
Table 4 Pregnancy outcomes among women whose weight gain was below recommended levels by guidelines of the Institute of Medicine

\begin{tabular}{|c|c|c|c|c|}
\hline \multirow[t]{2}{*}{ Outcome } & \multicolumn{2}{|l|}{$\mathrm{BMI}<25 \mathrm{~kg} / \mathrm{m}^{2}$} & \multicolumn{2}{|l|}{$\mathrm{BMI} \geq 25 \mathrm{~kg} / \mathrm{m}^{2}$} \\
\hline & Adjusted OR 95\% Cl & P-value & Adjusted OR 95\% Cl & P-value \\
\hline $\mathrm{GH}$ & $0.24[0.08-0.71]$ & 0.01 & $0.27[0.05-1.33]$ & 0.11 \\
\hline PE & $0.62[0.19-2.01]$ & 0.42 & NS & \\
\hline GDM & $2.55[1.54-4.23]$ & $<0.001$ & $2.16[0.87-5.38]$ & 0.10 \\
\hline $\mathrm{PPH}$ & $0.38[0.16-0.95]$ & 0.04 & $0.22[0.02-1.95]$ & 0.17 \\
\hline Cesarean section & $0.83[0.52-1.33]$ & 0.43 & $0.94[0.38-2.34]$ & 0.89 \\
\hline Assisted vaginal delivery & $0.88[0.42-1.84]$ & 0.73 & $1.18[0.14-10.02]$ & 0.88 \\
\hline Vaginal delivery & $1.23[0.79-1.92]$ & 0.35 & $1.06[0.43-2.63]$ & 0.90 \\
\hline Macrosomia & $0.78[0.28-2.14]$ & 0.63 & $0.26[0.02-3.37]$ & 0.30 \\
\hline SGA & $1.43[0.36-5.67]$ & 0.61 & NS & \\
\hline LGA & $0.54[0.25-1.16]$ & 0.11 & $1.05[0.34-3.23]$ & 0.93 \\
\hline
\end{tabular}

Data was analyzed using multivariable logistic regression analysis. Models were adjusted for maternal age, height, gravidity, parity, gestational age at delivery, cigarette smoke pre-pregnancy, and alcohol consumption pre-pregnancy

Reference group: adequate GWG in the same BMI category

$O R$ odds ratio, $C$ c confidence interval, GH gestational hypertension, $P E$ preeclampsia, GDM gestational diabetes mellitus, $P P H$ postpartum hemorrhage, SGA small for gestational age, LGA large for gestational age, NS the number in this category was too small to analyze

Table 5 Pregnancy outcomes among women whose weight gain was above recommended levels by guidelines of the Institute of Medicine

\begin{tabular}{|c|c|c|c|c|}
\hline \multirow[t]{2}{*}{ Outcome } & \multicolumn{2}{|l|}{$\mathrm{BMI}<25 \mathrm{~kg} / \mathrm{m}^{2}$} & \multicolumn{2}{|l|}{$\mathrm{BMI} \geq 25 \mathrm{~kg} / \mathrm{m}^{2}$} \\
\hline & Adjusted OR $95 \% \mathrm{Cl}$ & P-value & Adjusted OR 95\% Cl & P-value \\
\hline $\mathrm{GH}$ & $0.43[0.17-1.11]$ & 0.08 & $1.85[0.86-4.00]$ & 0.12 \\
\hline PE & $0.48[0.13-1.79]$ & 0.27 & $2.08[0.69-6.32]$ & 0.20 \\
\hline GDM & $0.31[0.14-0.72]$ & 0.006 & $0.56[0.27-1.17]$ & 0.12 \\
\hline $\mathrm{PPH}$ & $1.15[0.57-2.30]$ & 0.70 & $1.50[0.70-3.21]$ & 0.29 \\
\hline Cesarean section & $0.94[0.57-1.54]$ & 0.80 & $2.06[1.01-4.20]$ & 0.048 \\
\hline Assisted vaginal delivery & $0.88[0.42-1.83]$ & 0.72 & $0.43[0.07-2.74]$ & 0.37 \\
\hline Vaginal delivery & $1.10[0.70-1.73]$ & 0.69 & $0.56[0.28-1.12]$ & 0.10 \\
\hline Macrosomia & $1.90[0.87-4.17]$ & 0.11 & $2.17[0.69-6.79]$ & 0.19 \\
\hline SGA & $1.29[0.28-5.82]$ & 0.74 & NS & \\
\hline LGA & $2.41[1.40-4.18]$ & 0.002 & $1.53[0.73-3.23]$ & 0.26 \\
\hline
\end{tabular}

Data was analyzed using multivariable logistic regression analysis. Models were adjusted for maternal age, height, gravidity, parity, gestational age at delivery, cigarette smoke pre-pregnancy and alcohol consumption pre-pregnancy

Reference group: adequate GWG in the same BMI category

OR odds ratio, $\mathrm{Cl}$ confidence interval, $G H$ gestational hypertension, $P E$ preeclampsia, GDM gestational diabetes mellitus, $P P H$ postpartum hemorrhage, SGA small for gestational age, LGA large for gestational age, NS the number in this category was too small to analyze

compared with GWG within the IOM guidelines in the same BMI category. Therefore, these results indicate that women with a lower BMI could adhere to the IOM guidelines to obtain optimal fetal growth, since higher weight gain does not guarantee better pregnancy outcomes in this group of women.

In the present study, both overweight and obesity conditions increased the risk of $\mathrm{GH}$, but showed different effects on PE. Specifically, PE was associated with overweight but not obese women, which was contrary to previous reports. For example, a study conducted in Belgium found no significant differences in the prevalence of $\mathrm{GH}$ and preeclampsia between overweight and normal weight PCOS women [18]. The differences in findings could be possibly due to races and potential confounders. On the other hand, a study on general Chinese pregnant women revealed that underweight, overweight, and obese conditions increase the risk of GH [7], but they 
did not investigate whether various BMI has an impact on developing PE. Our results revealed that both overweight and obese PCOS women were more likely to give birth to LGA infants, whereas maternal overweight conditions increased the risk of macrosomia compared with normal weight women. However, there was no significant relationship between obesity and macrosomia, consistent with a previous retrospective study, which indicated that high BMI had no significant impact on the risk of delivering LGA newborn or macrosomia, in PCOS women who underwent frozen embryo transfer [19]. A study involving general pregnant Chinese women found that overweight and obese women were more prone to have LGA and macrosomia compared with normal weight counterparts [20]. A retrospective study involving 7122 general pregnant women from Bratislava, Slovakia, revealed that women with overweight and obesity had a 1.7- to 1.8fold risk of macrosomia compared with normal weight women [21], but the study did not examine the correlation between BMI and LGA birth. It might be partly that different ways of conception may have specific effects on pregnancy outcomes.

Based on the 2009 IOM guidelines, 45\% of the PCOS women in the present study achieved adequate weight gain during pregnancy, which was higher than the previously reported frequencies, including 29.6 and $30 \%$ in general and PCOS women, respectively $(22,23)$. This may be attributed to strict management regimes given to PCOS women at our hospital. Specifically, once PCOS women became pregnant, they were admitted to a specialized outpatient section where they received individualized medical nutritional therapy (MNT), as well as exercise guidance to help control weight gain during pregnancy.

We evaluated the effect of different GWG on PCOS women with $\mathrm{BMI} \geq 25 \mathrm{~kg} / \mathrm{m}^{2}$, However, we did not establish any relationship between various GWG and fetal growth in this BMI group. This is possibly related to the sample size in our study. On the other hand, GWG may play a relatively weak role in fetal growth. Therefore, this implies that more effort should be shifted to pre-conceptional weight management in PCOS women to achieve a normal weight. Previous studies have shown that overweight/obesity and PCOS are risk factors for GDM [24, 25]. In addition, early evidence suggests that clinical features of PCOS, such as polycystic ovaries, insulin resistance, and hyperandrogenism, might be potential factors of the GDM [26]. In the present study, we found a high incidence of GDM in overweight (30.2\%) and obese (36.5\%) PCOS women, relative to normal weight $(19.8 \%)$ counterparts, however, with no statistical significance following multivariate regression analysis. This could be attributed to the intervention for PCOS women before or during pregnancy. Moreover, different diagnostic criteria and the presence of heterogeneity between study populations could explain this.

From our results, it is evident that inadequate GWG is a protective factor for $\mathrm{GH}$ and $\mathrm{PPH}$ in women with pre-pregnancy $\mathrm{BMI}<25 \mathrm{~kg} / \mathrm{m}^{2}$, relative to those whose weight gain is within the optimal range in the same BMI category. However, we found no impact on overweight and obese pregnant women, indicating that GWG has different effects on $\mathrm{GH}$ and $\mathrm{PPH}$ across different BMI groups. In the future, large sample sized and multi-center studies should be conducted to validate these findings. Our results also indicated a positive relationship between excessive GWG and the incidence of cesarean section in women with $B M I \geq 25 \mathrm{~kg} / \mathrm{m}^{2}$, relative to those with weight gain within the IOM guidelines in the same BMI category. This was consistent with a previous study that associated high GWG with cesarean delivery in women with obesity class I (BMI $30.0-34.9 \mathrm{~kg} / \mathrm{m}^{2}$ ) compared with those who met gestational weight gain goals [27]. However, for women with $\mathrm{BMI} \geq 25 \mathrm{~kg} / \mathrm{m}^{2}$, inadequate GWG did not reduce the risk of LGA birth, which was consistent with our previous results showing that excessive GWG has no protective role in delivering an SGA newborn in women with $\mathrm{BMI}<25 \mathrm{~kg} / \mathrm{m}^{2}$. Our finding was inconsistent with the previous studies involving general pregnant women $[7,28]$. This could be attributed to the small number of SGA cases in our study. Besides, whether the factors entailing complicated endocrine and metabolism are involved in PCOS should be further investigated. Moreover, we found an inverse relationship between GWG and GDM, when PCOS women were diagnosed with GDM at 24-28 weeks' gestation, consistent with the findings of previous studies [7, 29]. To control weight gain and blood sugar levels, these women may undergo MNT, acquire exercise guidance, and insulin therapy when necessary, hence, the real association between GWG and GDM may have been masked. Therefore, further research is required to confirm the relationship between weight gain and the development of GDM among pregnant women with PCOS at different pregnancy periods.

Our study had several limitations. First, the pre-pregnancy body weights of the subjects were self-reported, at the first visit (week 6-8 or so). It is possible that recall bias may have occurred, thereby affecting the evaluation of BMI and GWG. Secondly, our study population mainly comprised subjects from the Beijing area, implying that our findings cannot be generalized to individuals from other Chinese regions or countries, because of the potential differences in education, socio-economic levels, as well as varying environmental factors. 


\section{Conclusions}

Our findings indicated that the correlations between pre-pregnancy BMI, GWG, and pregnancy outcomes among PCOS women, observed herein were similar to what has been previously reported in general women. However, some unique trends existed in PCOS women. Specifically, being underweight significantly increased the risk of SGA birth, overweight but not obesity was correlated with the risk of PE. Conversely, overweight or obese conditions were not associated with GDM, whereas inadequate GWG was a protective factor for $\mathrm{GH}$, and $\mathrm{PPH}$ only in women with pregestational $\mathrm{BMI}<25 \mathrm{~kg} / \mathrm{m}^{2}$. Inadequate $\mathrm{GWG}$ did not reduce the possibility of LGA birth in women with $\mathrm{BMI} \geq 25 \mathrm{~kg} /$ $\mathrm{m}^{2}$ and excessive GWG did not decrease the risk for $\mathrm{SGA}$ in women with $\mathrm{BMI}<25 \mathrm{~kg} / \mathrm{m}^{2}$. In general, prepregnancy BMI and GWG were shown to have different impacts on pregnancy outcomes between general and PCOS pregnant women. Taken together, these findings suggest that the management/intervention for PCOS women should focus on pre-conceptional weight management. Future studies should elucidate the ideal pre-pregnancy weight and ascertain the methods for appropriate weight gain during pregnancy.

\begin{abstract}
Abbreviations
PCOS: Polycystic ovary syndrome; BMI: Body mass index; GWG: Gestational weight gain; SGA: Small for gestational age; LGA: Large for gestational age; PPH: Postpartum hemorrhage; GDM: Gestational diabetes mellitus; PE: Preeclampsia; GH: Gestational hypertension; WHO: World Health Organization; ESHRE: European Society of Human Reproduction and Embryology; IOM: Institute of Medicine; MNT: Medical nutritional therapy; OR: Odds ratio; Cl: Confidence interval; SD: Standard deviations.
\end{abstract}

\section{Acknowledgements}

The authors thank the participants for participating in the study and the medical staff for their work on information collection.

\section{Authors' contributions \\ All the authors contributed significantly to the manuscript. LRZ was primarily responsible for the data analysis and writing of the manuscript. WZ signifi- cantly revised the draft, interpreted the data, and involved in data analyses. $\mathrm{CL}$ and $\mathrm{XL}$ collected the information and participated in data interpretation. $\mathrm{LZ}$ and $\mathrm{ZHT}$ involved in the data management and draft revision. GHL was responsible for designing the study and critically revising the manuscript. All authors read and approved the final manuscript.}

\section{Funding}

This study was supported by National Key Research and Development Program of China (Grant Number 2016YFC1000304), National Natural Science Foundation of China (Grant Number 81671477), Beijing Municipal Science and Technology Commission (Grant/Award Number: Z161100000516160).

\section{Availability of data and materials}

The data is available upon reasonable request to the corresponding author.

\section{Ethics approval and consent to participate}

The study was approved by the Ethics Committee of Beijing Obstetrics and Gynecology Hospital (2012-KY-012, 2016-KY-066). Written informed consent was obtained from all participants. All procedures were performed in compliance with the Declaration of Helsinki.

\section{Consent for publication}

Not applicable.

\section{Competing interests}

The authors declare that they have no competing interests.

Received: 16 July 2020 Accepted: 29 September 2020

Published online: 08 October 2020

\section{References}

1. Azziz R, Carmina E, Chen Z, Dunaif A, Laven JSE, Legro RS, et al. Polycystic ovary syndrome. Nat Rev Dis Primers. 2016;2(1):1-8.

2. Witchel SF, Burghard AC, Tao RH, Oberfield SE. The diagnosis and treatment of PCOS in adolescents: an update. J Curr Opin Pediatr. 2019:31(4):562-9.

3. Palomba S, de Wilde MA, Falbo A, Koster MP, La Sala GB, Fauser BC. Pregnancy complications in women with polycystic ovary syndrome. Hum Reprod Update. 2015;21(5):575-92.

4. Lim SS, Norman RJ, Davies MJ, Moran LJ. The effect of obesity on polycystic ovary syndrome: a systematic review and meta-analysis. Obes Rev. 2013;14(2):95-109.

5. Bahri Khomami M, Joham AE, Boyle JA, Piltonen T, Arora C, Silagy M, et al. The role of maternal obesity in infant outcomes in polycystic ovary syndrome-a systematic review, meta-analysis, and meta-regression. Obes Rev. 2019;20(6):842-58.

6. Arusoglu G, Koksal G, Cinar N, Tapan S, Aksoy DY, Yildiz BO. Basal and meal-stimulated ghrelin, PYY, CCK levels and satiety in lean women with polycystic ovary syndrome: effect of low-dose oral contraceptive. J Clin Endocrinol Metab. 2013;98(11):4475-82.

7. Li C, Liu Y, Zhang W. Joint and independent associations of gestational weight gain and pre-pregnancy body mass index with outcomes of pregnancy in Chinese women: a retrospective cohort study. PLOS ONE. 2015;10(8):e0136850.

8. American College of Obstetricians and Gynecologists. ACOG Committee opinion no. 548: weight gain during pregnancy. Obstet Gynecol. 2013;121(1):210-2.

9. Li G, Kong L, Li Z, Zhang L, Fan L, Zou L, et al. Prevalence of macrosomia and its risk factors in China: a multicentre survey based on birth data involving 101723 singleton term infants. Paediatr Perinat Epidemiol. 2014;28(4):345-50.

10. Simmons D, Devlieger R, van Assche A, Galjaard S, Corcoy R, Adelantado $J M$, et al. Association between gestational weight gain, gestational diabetes risk, and obstetric outcomes: a randomized controlled trial post hoc analysis. Nutrients. 2018;10(11):1568.

11. Rotterdam EA-SPCWG. Revised 2003 consensus on diagnostic criteria and long-term health risks related to polycystic ovary syndrome. Fertil Steril. 2004;81(1):19-25.

12. Bernard N, Forest JC, Tarabulsy GM, Bujold E, Bouvier D, Giguere Y. Use of antidepressants and anxiolytics in early pregnancy and the risk of preeclampsia and gestational hypertension: a prospective study. BMC Pregnancy Childbirth. 2019;19(1):146.

13. Williamson RD, McCarthy FP, Kenny LC, McCarthy CM. Activation of a TLR9 mediated innate immune response in preeclampsia. Sci Rep. 2019;9(1):5920.

14. Villar J, Ismail LC, Victora CG, et al. International standards for newborn weight, length, and head circumference by gestational age and sex: the Newborn Cross-Sectional Study of the INTERGROWTH-21st Project. Lancet. 2014;384(9946):857-68.

15. Liu P, Xu L, Wang Y, Zhang Y, Du Y, Sun Y, et al. Association between perinatal outcomes and maternal pre-pregnancy body mass index. Obes Rev. 2016;17(11):1091-102.

16. El Rafei R, Abbas HA, Charafeddine L, Nakad P, Al Bizri A, Hamod D, et al. Association of pre-pregnancy body mass index and gestational weight gain with preterm births and fetal size: an observational study from Lebanon. Paediatr Perinat Epidemiol. 2016;30(1):38-45.

17. Hai-Feng Yu, Chen H-S, Rao D-P, Gong J. Association between polycystic ovary syndrome and the risk of pregnancy complications. Medicine. 2016:95(51):e4863. 
18. De Frene V, Vansteelandt S, T'Sjoen G, Gerris J, Somers S, Vercruysse L, et al. A retrospective study of the pregnancy, delivery and neonatal outcome in overweight versus normal weight women with polycystic ovary syndrome. Hum Reprod. 2014;29(10):2333-8.

19. Lin J, Huang J, Wang N, Kuang Y, Cai R. Effects of pre-pregnancy body mass index on pregnancy and perinatal outcomes in women with PCOS undergoing frozen embryo transfer. BMC Pregnancy Childbirth. 2019;19(1):487.

20. Su WJ, Chen YL, Huang PY, Shi XL, Yan FF, Chen Z, et al. Effects of prepregnancy body mass index, weight gain, and gestational diabetes mellitus on pregnancy outcomes: a population-based study in Xiamen, China, 2011-2018. Ann Nutr Metab. 2019;75(1):31-8.

21. Simko M, Totka A, Vondrova D, Samohyl M, Jurkovicova J, Trnka M, et al. Maternal body mass index and gestational weight gain and their association with pregnancy complications and perinatal conditions. Int J Environ Res Public Health. 2019;16(10):1751.

22. Huang A, Ji Z, Zhao W, Hu H, Yang Q, Chen D. Rate of gestational weight gain and preterm birth in relation to prepregnancy body mass indices and trimester: a follow-up study in China. Reprod Health. 2016;13(1):93.

23. Kent J, Dodson WC, et al. Gestational weight gain in women with polycystic ovary syndrome: a controlled study. J Clin Endocrinol Metab Endocr Soc. 2018;103:4315-23.

24. Mikola M, Hiilesmaa V, Halttunen M, Suhonen L, Tiitinen A. Obstetric outcome in women with polycystic ovarian syndrome. Hum Reprod. 2001;16(2):226-9.
25. Mustaniemi S, Vaarasmaki M, Eriksson JG, Gissler M, Laivuori H, ljas H, et al. Polycystic ovary syndrome and risk factors for gestational diabetes. Endocr Connect. 2018;7(7):859-69.

26. Sayin NC, Gücer F, Balkanli-Kaplan P, Yüce MA, Yardim T. Insulin resistance and lipid profile in women with polycystic appearing ovaries implications with regard to polycystic ovary syndrome. Gynecol Endocrinol. 2003;17(5):387-96.

27. Kominiarek MA, Seligman NS, Dolin C, Gao W, Berghella V, Hoffman M, et al. Gestational weight gain and obesity: is 20 pounds too much? Am J Obstet Gynecol. 2013;209(3):214.e1-e11.

28. Hung TH, Hsieh TT. Pregestational body mass index, gestational weight gain, and risks for adverse pregnancy outcomes among Taiwanese women: a retrospective cohort study. Taiwan J Obstet Gynecol. 2016;55(4):575-81.

29. Yang W, Han F, Gao X, Chen Y, Ji L, Cai X. Relationship between gestational weight gain and pregnancy complications or delivery outcome. Sci Rep. 2017;7(1):12531.

\section{Publisher's Note}

Springer Nature remains neutral with regard to jurisdictional claims in published maps and institutional affiliations.
Ready to submit your research? Choose BMC and benefit from:

- fast, convenient online submission

- thorough peer review by experienced researchers in your field

- rapid publication on acceptance

- support for research data, including large and complex data types

- gold Open Access which fosters wider collaboration and increased citations

- maximum visibility for your research: over $100 \mathrm{M}$ website views per year

At BMC, research is always in progress.

Learn more biomedcentral.com/submissions 